\title{
Erratum to: Chemical and electrochemical grafting of polythiophene onto poly(vinyl chloride): synthesis, characterization, and materials properties
}

\author{
Bakhshali Massoumi $^{1} \cdot$ Amir Farnoudiyan-Habibi $^{2} \cdot$ Mehdi Jaymand $^{3}$
}

Received: 9 January 2017 / Accepted: 11 January 2017 /Published online: 17 January 2017

(C) Springer-Verlag Berlin Heidelberg 2017

Erratum to: J Solid State Electrochem (2016) 20:489-497

DOI 10.1007/s10008-015-3070-x

The authors regret that the surname of one author was misspelt in the article, it should be Amir Farnoudiyan-Habibi. In addition, the affiliation for the author was incorrect and it should be "Young Researchers and Elite Club, Tabriz Branch, Islamic Azad University, P.O. Box: 5157944533, Tabriz, Islamic Republic of Iran".

We apologize for the error, and we regret any confusion or inconvenience it may have caused.

Kind regards,

Mehdi Jaymand (on behalf of the authors)

The online version of the original article can be found at http://dx.doi. org/10.1007/s10008-015-3070-x.

Mehdi Jaymand

m_jaymand@yahoo.com; m.jaymand@gmail.com;

jaymandm@tbzmed.ac.ir

1 Department of Chemistry, Payame Noor University, P.O. Box: 19395-3697, Tehran, Islamic Republic of Iran

2 Young Researchers and Elite Club, Tabriz Branch, Islamic Azad University, P.O. Box: 5157944533, Tabriz, Islamic Republic of Iran

3 Research Center for Pharmaceutical Nanotechnology, Tabriz University of Medical Sciences, P.O. Box: 51656-65811,

Tabriz, Islamic Republic of Iran 